\title{
Insertion Homo- and Copolymerization of Diallyl Ether
}

\author{
Zhongbao Jian and Stefan Mecking*
}

\begin{abstract}
The previously unresolved issue of polymerization of allyl monomers $\mathrm{CH}_{2}=\mathrm{CHCH}_{2} \mathrm{X}$ is overcome by a palla dium catalyzed insertion polymerization of diallyl ether as a monomer. An enhanced 2,1 insertion of diallyl ether as compared to mono allyl ether retards the formation of an unreactive five membered cyclic $O$ chelate (after 1,2 insertion) that otherwise hinders further polymerization, and also enhances incorporation in ethylene polymers $(20.4 \mathrm{~mol} \%)$. Cyclic ether repeat units are formed selectively $(96 \%$ 99\%) by an intramolecular insertion of the second allyl moiety of the monomer. These features even enable a homopolymerization to yield polymers (poly diallyl ether) with degrees of polymer ization of $D P_{n} \approx 44$.
\end{abstract}

$V_{\text {i }}$

nyl polymers are employed on a vast scale for a myriad of applications. Prominent examples are acrylate and methacry late polymers, poly(vinyl chloride), or vinyl acetate homo and copolymers. By contrast, a (co)polymerization of polar allyl monomers $\mathrm{CH}_{2}=\mathrm{CHCH}_{2} \mathrm{X}$ has remained largely elusive.

A free radical ${ }^{[1,2]}$ or cationic $^{[3]}$ polymerization of allyl monomers is suppressed presumably by the formation of stable $\pi$ allyl radicals or cations, respectively, that retard or terminate the chain growth reaction. Recently, a coordina tion insertion copolymerization of polar allyl monomer with ethylene has been found to be possible. ${ }^{[4]}$ Various allyl monomers (for example $\mathrm{X}=\mathrm{OAc}, \mathrm{OH}, \mathrm{NR}_{2}, \mathrm{Cl}$, acrylate) were copolymerized with ethylene using nickel or palladium catalysts. ${ }^{[5]}$ Despite these significant achievements, the catalytic activities are limited and the allyl monomer incor poration is relatively low $(0.17 .9 \mathrm{~mol} \%)$. The origin of these limitations remains unclear to date. We now report studies of diallyl ether insertion and polymerization reactivity that illuminate these issues and reveal an approach to overcome them, even allowing for an insertion homopolymerization.

Copolymerizations of allyl ethyl ether (AEE) and ethyl ene (E) were performed using the dianisyl phosphinesulfo nato palladium catalyst precursor $\mathbf{1}$, which is well established for polar vinyl monomer insertion polymerizations. $\left.{ }^{[8} 10\right]$ Under pressure reactor conditions, exposure of $\mathbf{1}$ to 5 bar of $\mathrm{E}$ and $0.1 \mathrm{M}$ of $\mathrm{AEE}$ at $80^{\circ} \mathrm{C}$ resulted in the formation of a copolymer with a low AEE incorporation of $0.8 \mathrm{~mol} \%$ (Table 1, entry 1) ${ }^{[11]}$ Increasing the concentration of AEE led to an increase of AEE incorporation in the copolymers along

[*] Dr. Z. Jian, Prof. Dr. S. Mecking

Chair of Chemical Materials Science

Department of Chemistry, University of Konstanz

Universitätsstrasse 10, 78457 Konstanz (Germany)

E mail: stefan.mecking@uni konstanz.de with a decrease in catalytic activity and molecular weight (Table 1, entries 2 5). However, the AEE incorporations were limited to only $4.0 \mathrm{~mol} \%$. These low incorporations agree with the polymerization behavior of other polar allyl monomers reported previously. ${ }^{[5 c]}$ With the aim of enhancing the co monomer incorporation, a further allyl monomer acrolein diethyl acetal (ADEA) ${ }^{[12]}$ was also tested in the copolymerization reaction (Table 1, entries 6 versus 3 ). How ever, the co monomer incorporation almost remains unal tered.

Surprisingly, for diallyl ether (DAE) as a monomer under otherwise identical reaction conditions $(0.1 \mathrm{M})$, catalytic activity and co monomer incorporation in the reaction with E are enhanced versus AEE (Table 2, entry 1 versus Table 1, entry 1). As expected, at a given E pressure, the incorporation of DAE in the copolymers increases with increasing concen tration of the co monomer in the reaction mixture to reach $20.4 \mathrm{~mol} \%$ at an initial concentration $[\mathrm{DAE}]=1.2 \mathrm{~mol} \mathrm{~L}^{-1}$ (Table 2, entries 2 7). This high incorporation of electron rich allyl monomer DAE matches with the most favorable electron poor vinyl monomers such as acrylate reported to date. ${ }^{[9 f, 13,14]}$ A lower temperature results in a decreased incorporation of DAE (Table 2, entries 8 and 9 vs. 3). Consistently throughout these copolymerization studies (Tables 1 and 2), not only catalytic activity $\left(\mathrm{TOF}_{\mathrm{E}}\right.$ and $\mathrm{TOF}_{\mathrm{DAE}}$ ) but also co monomer incorporation of DAE are higher compared to the mono allyl analogue AEE. Note that incorporations are given on the basis of molecules of DAE incorporated, that is, the amount of allyl moieties incorpo rated (see below) is twice as high owing to the difunctional character of DAE.

To account for these observations, polymer microstruc tures were analyzed. According to the quantitative ${ }^{13} \mathrm{C} N M R$ spectrum (Supporting Information, Figure S30), the E AEE copolymer possesses a highly linear polyethylene backbone. AEE is incorporated primarily into the polymer main chain. Chain end analysis indicates that AEE is incorporated into saturated initiating chain ends, but it is not detected in unsaturated terminating chain ends. ${ }^{[15]}$ For the E DAE copolymers, a richer variety of microstructure motifs results from the possible reaction pathways of the two allylic double bonds of the monomer. In principle, an incorporation of DAE can occur in a non cyclic fashion (repeat unit $\mathbf{I}$, arising from insertion into alkyls $\mathbf{2}, \mathbf{5}$, and $\mathbf{6}$ in Scheme 1) or yield cyclic structures (II from 4; III from 3, 7; or IV from 8). To illuminate the regio and stereochemistry of the polymers, ethylene $d_{4}$ and DAE were copolymerized with $\mathbf{1}$.

The resulting copolymers feature ${ }^{1} \mathrm{H}$ NMR resonances at $\delta=3.97$ and $3.42\left(\mathrm{CH}_{2} \mathrm{O}\right), 1.80(\mathrm{CH}), 1.55$ and $1.33 \mathrm{ppm}$ $\left(\mathrm{CH}_{2}\right)$ with an integral ratio of ca. 2:1:2, arising from trans II units (Figure 1). COSY and TOCSY2D experiments further confirm that these resonances at $\delta=3.91$ and 3.50, 2.16, 1.45 
Table 1: Copolymerization of ethylene with allyl ether and acrolein diethyl acetal. ${ }^{[a]}$

\begin{tabular}{|c|c|c|c|c|c|c|c|c|c|c|}
\hline \multirow[t]{2}{*}{ Entry } & \multirow[t]{2}{*}{ Monomer } & \multirow[t]{2}{*}{ Conc. [mol L ' $]$} & \multirow[t]{2}{*}{$t[\mathrm{~h}]$} & \multirow[t]{2}{*}{ Yield [mg] } & \multicolumn{2}{|c|}{$\mathrm{TOF}^{[\mathrm{b}]}$} & \multirow[t]{2}{*}{ Incorp. ${ }^{[c]}[\mathrm{mol} \%]$} & \multirow[t]{2}{*}{$M_{\mathrm{n}}{ }^{[\mathrm{d}]}\left[\mathrm{g} \mathrm{mol}^{1}\right]$} & \multirow[t]{2}{*}{$M_{\mathrm{w}} / M_{\mathrm{n}}^{[\mathrm{d}]}$} & \multirow[t]{2}{*}{$T_{\mathrm{m}}{ }^{[\mathrm{e}]}\left[{ }^{\circ} \mathrm{C}\right]$} \\
\hline & & & & & $\mathrm{E}$ & AEE & & & & \\
\hline 1 & AEE & 0.1 & 2 & 160 & 140 & 1.1 & 0.8 & 3800 & 1.9 & 123 \\
\hline 2 & AEE & 0.2 & 5 & 150 & 51 & 0.7 & 1.4 & 3700 & 1.8 & 120 \\
\hline 3 & AEE & 0.3 & 7 & 180 & 43 & 1.0 & 2.3 & 3300 & 1.8 & 114 \\
\hline 4 & AEE & 0.4 & 12 & 220 & 30 & 0.9 & 2.9 & 3000 & 1.8 & 109 \\
\hline 5 & AEE & 0.6 & 17 & 180 & 17 & 0.7 & 4.0 & 2500 & 1.7 & 104 \\
\hline 6 & ADEA & 0.3 & 4 & 120 & 49 & 1.0 & 2.1 & 3100 & 2.3 & 115 \\
\hline
\end{tabular}

[a] Reaction conditions: toluene + monomer, $50 \mathrm{~mL} ; 80^{\circ} \mathrm{C}$; catalyst precursor 1, 20 umol; ethylene, 5 bar; 1000 rpm; unless noted otherwise. [b] Units: mol mol ${ }_{\mathrm{Pd}}{ }^{1} \mathrm{~h}{ }^{1}$. [c] Determined by ${ }^{1} \mathrm{H}$ NMR spectroscopy in $\mathrm{C}_{2} \mathrm{D}_{2} \mathrm{Cl}_{4}$ at $130^{\circ} \mathrm{C}$. [d] Determined by $\mathrm{GPC}$ in $1,2,4$ trichlorobenzene at $160^{\circ} \mathrm{C}$ versus linear polyethylene. [e] Determined by DSC.

Table 2: Copolymerization of ethylene with diallyl ether. ${ }^{[a]}$

\begin{tabular}{|c|c|c|c|c|c|c|c|c|c|c|c|c|c|c|}
\hline \multirow[t]{2}{*}{ Entry } & \multirow{2}{*}{$\begin{array}{c}\text { Conc. } \\
{\left[\mathrm{mol} \mathrm{L}^{1}\right]}\end{array}$} & \multirow[t]{2}{*}{$t[\mathrm{~h}]$} & \multirow{2}{*}{$\begin{array}{l}\text { Yield } \\
{[\mathrm{mg}]}\end{array}$} & \multicolumn{2}{|c|}{$\mathrm{TOF}^{[\mathrm{b}]}$} & \multirow{2}{*}{$\begin{array}{l}\text { Incorp. }^{[\mathrm{c}]} \\
{[\mathrm{mol} \%]}\end{array}$} & \multirow[b]{2}{*}{ I } & \multicolumn{4}{|c|}{ Microstructure $\mathrm{e}^{[\mathrm{c}]}[\%]$} & \multirow{2}{*}{$\begin{array}{c}M_{\mathrm{n}}^{[\mathrm{d}]} \\
{\left[\mathrm{g} \mathrm{mol}^{\mathrm{l}}\right]}\end{array}$} & \multirow{2}{*}{$\begin{array}{l}M_{w} / \\
M_{n}^{[d]}\end{array}$} & \multirow{2}{*}{$\begin{array}{l}T_{\mathrm{m}}{ }^{[\mathrm{e}]} \\
{\left[{ }^{\circ} \mathrm{C}\right]}\end{array}$} \\
\hline & & & & $E$ & DAE & & & $\begin{array}{l}\text { cis- } \\
\text { II }\end{array}$ & $\begin{array}{c}\text { trans- } \\
\text { II }\end{array}$ & $\begin{array}{l}\text { cis- } \\
\text { III }\end{array}$ & $\begin{array}{c}\text { trans- } \\
\text { III }\end{array}$ & & & \\
\hline 1 & 0.1 & 1 & 290 & 479 & 11.3 & 2.3 & 1.2 & 3.9 & 68.9 & 11.3 & 14.7 & 5900 & 2.1 & 118 \\
\hline 2 & 0.2 & 2.5 & 300 & 185 & 8.3 & 4.3 & 1.6 & 3.1 & 62.5 & 12.5 & 20.3 & 5500 & 2.1 & 111 \\
\hline 3 & 0.3 & 4 & 300 & 108 & 7.5 & 6.5 & 1.8 & 3.4 & 60.4 & 13.2 & 21.2 & 4100 & 2.4 & 100 \\
\hline 4 & 0.4 & 5.5 & 240 & 60 & 5.1 & 7.9 & 2.2 & 3.6 & 60.0 & 13.5 & 20.7 & 4000 & 2.1 & 95 \\
\hline 5 & 0.6 & 7 & 180 & 32 & 4.1 & 11.4 & 2.4 & 3.9 & 59.7 & 13.5 & 20.5 & 3200 & 1.8 & 82 \\
\hline 6 & 0.8 & 13 & 160 & 14 & 2.2 & 13.5 & 3.2 & 4.0 & 59.4 & 13.8 & 19.6 & 3100 & 1.8 & 76 \\
\hline 7 & 1.2 & 16 & 190 & 11 & 2.8 & 20.4 & 3.6 & 5.5 & 56.5 & 12.6 & 21.8 & 2300 & 1.7 & 52 \\
\hline $8^{[\mathrm{f}]}$ & 0.3 & 16 & 55 & 6 & 0.1 & 2.3 & 0.9 & 5.8 & 82.6 & 4.4 & 6.3 & 3700 & 2.4 & 119 \\
\hline $9^{[g]}$ & 0.3 & 7 & 130 & 28 & 1.6 & 5.5 & 0.8 & 3.6 & 66.6 & 12.0 & 17.0 & 4000 & 2.5 & 101 \\
\hline $10^{[\mathrm{h}]}$ & 0.6 & 7 & 840 & 207 & $2.7^{[]}$ & $1.3^{[]}$ & & [17] & & & & 1800 & 1.8 & 121 \\
\hline
\end{tabular}

[a] Reaction conditions: toluene + diallyl ether, $50 \mathrm{~mL} ; 80^{\circ} \mathrm{C}$; catalyst precursor 1,20 mol ; ethylene, 5 bar; $1000 \mathrm{rpm}$; unless noted otherwise. [b] Units: molmol ${ }_{\mathrm{Pd}}{ }^{1} \mathrm{~h}{ }^{1}$. [c] Determined by ${ }^{7} \mathrm{H}$ NMR spectroscopy in $\mathrm{C}_{2} \mathrm{D}_{2} \mathrm{Cl}_{4}$ at $130^{\circ} \mathrm{C}$. [d] Determined by $\mathrm{GPC}$ in $1,2,4$ trichlorobenzene at $160^{\circ} \mathrm{C}$ versus linear polyethylene. [e] Determined by DSC. [f] Polymerization temperature: $30^{\circ} \mathrm{C}$. [g] Polymerization temperature: $60^{\circ} \mathrm{C}$. [h] Monomer: 2,5 dihydrofuran. [i] TOF and incorporation of 2,5 dihydrofuran, respectively.

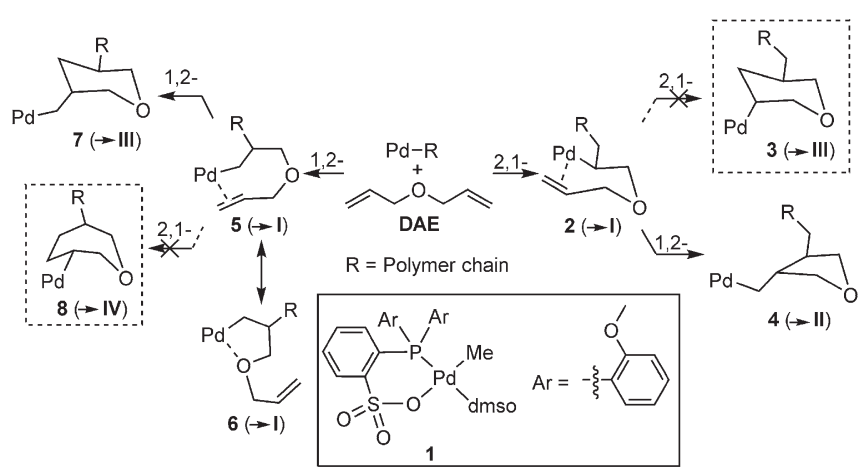

Scheme 1. Possible microstructures after insertion of DAE into Pd R.

and $1.28 \mathrm{ppm} ; 3.92$ and 2.92, 1.62, 1.95 and $0.75,1.17 \mathrm{ppm}$; 3.68 and $3.36,1.66,1.55,1.39$ and 1.29 ppm originate from cis II, cis III, and trans III, respectively (Supporting Information, Figures S31 S37). The non cyclic motif $\mathbf{I}$ gives rise to four identifiable multiplets at $\delta=5.96,5.30$ and 5.19, $3.99 \mathrm{ppm}$, respectively. Seven membered cycles (IV) were not found.

1D and 2D NMR analyses of all E DAE copolymers reveal a highly linear microstructure (ca. 12 methyl

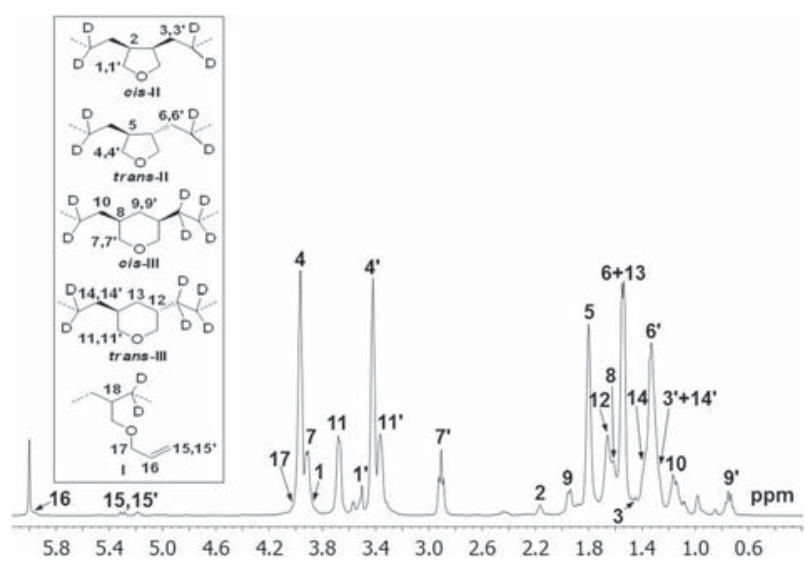

Figure 1. ${ }^{1} \mathrm{H} N M R$ spectrum $\left(600 \mathrm{MHz}, 120^{\circ} \mathrm{C}, \mathrm{C}_{2} \mathrm{D}_{2} \mathrm{Cl}_{4}\right)$ of an ethyl ene $d_{4}$ DAE copolymer obtained with 1 .

branches/1000 C) with cyclic and non cyclic structures incor porated in the main chain (Supporting Information, Figur es S38 S46). Notably, E DAE copolymers with virtually exclusively cyclic units are accessible (96\% 99\%). That is, an initial insertion of DAE into the growing polymer chain is 
succeeded by an insertion of the second allylic double bond of the monomer (Scheme 1), rather than by an insertion of E. A similar scenario has been observed recently in the established acrylate copolymerization with $\mathbf{1}$, using a di vinyl mono mer. $^{[13]}$

Within the cyclic motifs of E DAE copolymers, the content of five membered cyclic structure II, in which transII predominates, is circa twofold higher than that of the six membered cyclic structure III. ${ }^{[16]}$ Additionally, ATR IR spectra of E DAE copolymers feature characteristic bands at 1096 and $1047 \mathrm{~cm}^{-1}, 925 \mathrm{~cm}^{-1}$, assigned to $v(\mathrm{C} \mathrm{O} \mathrm{C)}$ of III and II, respectively (Supporting Information, Figure S53). The predominant cyclic repeat units II in the E DAE copolymers resemble a copolymer of ethylene and 2,5 dihydrofuran. Probing such a copolymerization for compar ison (entry 10 vs. entry 5 in Table 2), the incorporation of 2,5 dihydrofuran is low $(1.3 \mathrm{~mol} \%),{ }^{[17]}$ however, compared to $11.4 \mathrm{~mol} \%$ for DAE (7.3 mol \% for tetrahydrofuran structure II).

The underlying insertion events were elucidated by stoichiometric NMR studies (Supporting Information, Fig ures S1 S4). Under pseudo first order conditions (excess monomer, ca. 20 equiv), the insertion of AEE into the Pd Me bond of 1 at $25^{\circ} \mathrm{C}$ overwhelmingly yields the 1,2 insertion product $(1,2: 2,1=$ ca. $10: 1$ within $1 \mathrm{~h})$ with an observed rate constant $\left(k_{1}^{\mathrm{AEE}}\right)$ of $18.5 \times 10^{-4} \mathrm{~s}^{-1}$ (Scheme 2$)$. Note that, even over prolonged reaction times, no second insertion is detected, indicating that the first AEE 1.2 insertion product is very stable, which is due to chelating coordination of the ether oxygen atom (see below). Under otherwise identical conditions, the observed rate constant $\left(k_{1}^{\mathrm{DAE}}=23.0 \times 10^{-4} \mathrm{~s}^{-1}\right)$ for the insertion of DAE into the Pd Me bond of $\mathbf{1}$ is higher. However, unexpectedly, the preference for 1,2 over 2,1 insertion (Scheme 2, 6 vs. 2 ) is strongly decreased to only ca. $2: 1$ as observed after ca. $1 \mathrm{~h}$ of reaction time. Owing to the presence of a stable five membered $O$ chelate in the 1,2 product, the rate of intramolecular insertion of the remaining second double bond in $\mathbf{6}$ (to form 7) is much slower than for the 2,1 insertion product 2 (to form 4$)\left(k_{2} \ll k_{2}^{\prime}\right.$; Supporting Information, Figures S3 and S23). Accordingly, over a pro longed time of ca. $17 \mathrm{~h}$, the intensity of signals from 2,1 insertion products containing tetrahydrofuran structures (such as the tetrahydrofuran ring in 4) increases gradually, and is higher than those from 1,2 inser tion product $(\mathbf{6})$ by a factor of ca 1.5 (Supporting Information, Figure S3). In a short conclusion based on kinetic experiments: 1) 1,2 insertion of DAE into the Pd Me bond of $\mathbf{1}$ is preferred, but this preference is not very pro nounced $(1,2: 2,1=\mathrm{ca} .2: 1)$ and much lower than that observed for $\mathrm{AEE}$ $(1,2: 2,1=$ ca. $10: 1) ; 2)$ after insertions, with the increase of bulk of Pd alkyl bonds, 1,2 favored insertion of DAE gradually converts into 2,1 favored insertion; 3) therefore it appears reason able that, for insertion of DAE into more bulky palladium alkyl bonds (such
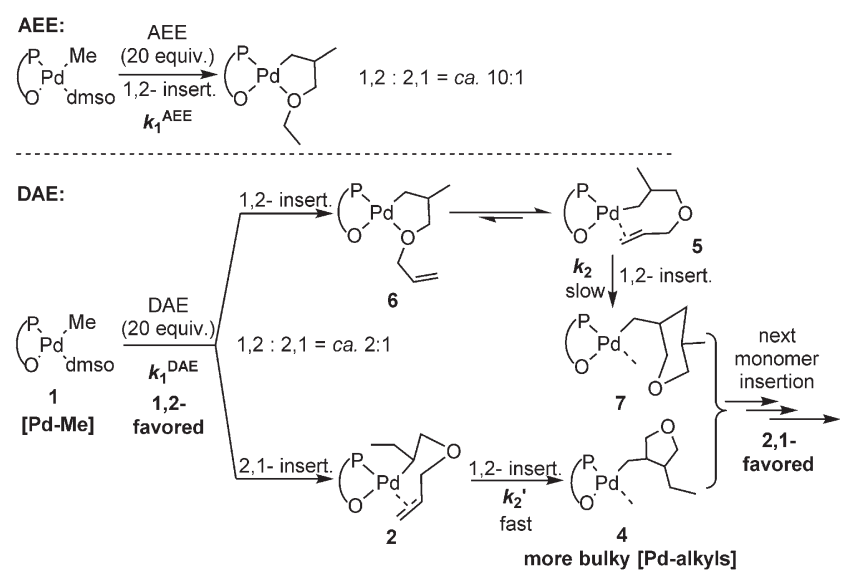

Scheme 2. Stoichiometric insertion studies.

as analogues of $\mathbf{4}$ and $\mathbf{7}$ in Scheme 2) during chain growth, 2,1 insertion can actually be favored. This mechanistic consider ation based on kinetic experiments of DAE is consistent with the observed E DAE copolymer microstructures, where the amount of tetrahydrofuran structures derived from 2,1 insertion of DAE into palladium polyethylene growing chains (more bulky palladium alkyl bonds) is higher than that of tetrahydropyran structures derived from 1,2 insertion of DAE (columns cis II/trans II versus cis III/trans III, Table 2). ${ }^{[18]}$ The altered regioselectivity from 1,2 to 2,1 is crucial in the DAE polymerization, as it reduces the formation of chelated 1,2 product that seriously retards chain growth

The key 1,2 insertion product 9 from the reaction of AEE with 1 (Scheme 3) could be isolated and fully characterized by NMR spectroscopy $\left(\mathbf{9 : 9 ^ { \prime }}=10: 1\right.$; Supporting Information, Figures S5 S9). The solid state structure of $\mathbf{9}$, as determined by single crystal $\mathrm{X}$ ray diffraction, unambiguously confirms the presence of a five membered cyclic chelate (Scheme 3). As outlined, under otherwise identical conditions, the reac tion of DAE with 1 gave products $\mathbf{6}(1,2)$ and $\mathbf{4}$ dmso $(2,11,2)$ in the ratio of ca. 2:1. To confirm their structures, the pyridine adducts $\mathbf{6}$ pyridine and $\mathbf{4}$ pyridine that are more easily analyzed owing to well separated proton signals in the ${ }^{1} \mathrm{H}$ NMR spectrum were also generated. As shown in the

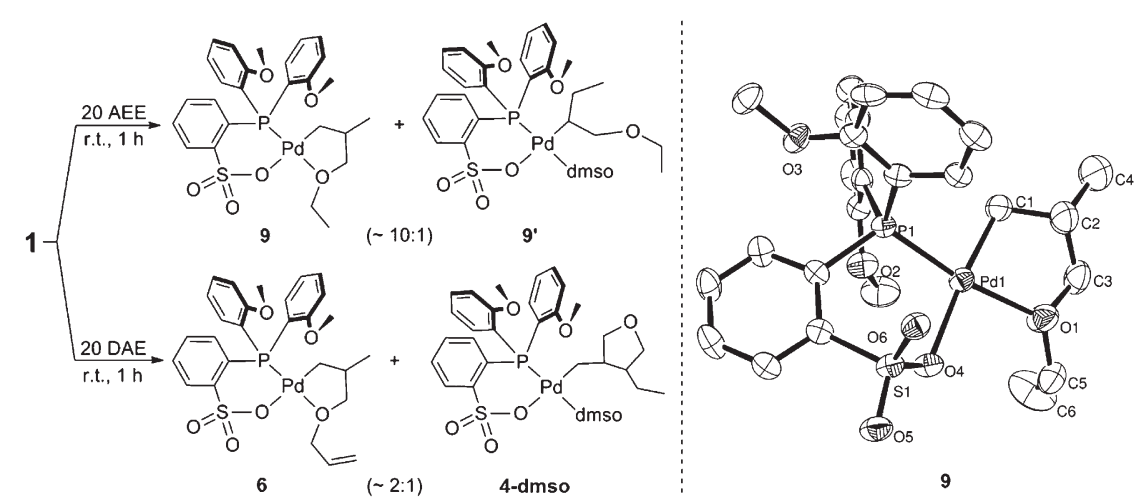

Scheme 3. Synthesis of insertion products (left)and structure of $\mathbf{9}$ shown as an ORTEP (right, ellipsoids set at $50 \%$ probability with hydrogen atoms omitted for clarity). ${ }^{[9]}$ 
Supporting Information, Figures S10 S22, signals in 1D and 2D NMR spectra could be assigned to the different products.

These findings also suggested the possibility of a homo polymerization of allyl monomers. In a control experiment without added catalyst precursor or other initiators, DAE was found to be unreactive (Table 3, entry 1 ). In the presence of $\mathbf{1}$, DAE homopolymers were formed with moderate activities

Table 3: Homopolymerization of diallyl ether. ${ }^{[a]}$

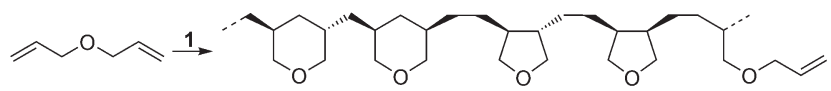

\begin{tabular}{llllll}
\hline Entry & Cat. & Yield $[\mathrm{mg}]$ & $\mathrm{TOF}^{[\mathrm{b}]}$ & $M_{\mathrm{n}}{ }^{[\mathrm{c}]}\left[\mathrm{gmol}^{1}\right]$ & $M_{\mathrm{w}} / M_{\mathrm{n}}^{[\mathrm{c}]}$ \\
\hline 1 & & & & & \\
2 & 1 & 110 & 4.7 & 3660 & 1.3 \\
$3^{[\mathrm{d}]}$ & 1 & 200 & 4.3 & 3970 & 1.4 \\
$4^{[\mathrm{e}]}$ & 1 & 140 & 5.9 & 3970 & 1.4 \\
$5^{[\mathrm{f}]}$ & 1 & 190 & 8.1 & 4350 & 1.7 \\
6 & $\mathrm{AlBN}$ & 35 & 1.1 & & \\
7 & {$\left[\mathrm{Ph}_{3} \mathrm{C}\right]\left[\mathrm{B}\left(\mathrm{C}_{6} \mathrm{~F}_{5}\right)_{4}\right]$} & 50 & 3.2 & & \\
$8^{[\mathrm{g}]}$ & 1 & 15 & 0.7 & & \\
\hline
\end{tabular}

[a] Reaction conditions: toluene + monomer, $5 \mathrm{~mL} ; 80^{\circ} \mathrm{C} ; 4 \mathrm{~h}$; diallyl ether, 225 equiv; $\left[\mathrm{Ph}_{3} \mathrm{C}\right]\left[\mathrm{B}\left(\mathrm{C}_{6} \mathrm{~F}_{5}\right)_{4}\right], 40 \mu \mathrm{mol}$ or $\mathrm{AIBN}, 80 \mu \mathrm{mol}$ or catalyst precursor 1, $60 \mu \mathrm{mol}$; unless noted otherwise. [b] Units: mol mol ${ }_{\mathrm{Pd}}{ }^{1} \mathrm{~h}{ }^{1}$. [c] Determined by GPC in THF at $40^{\circ} \mathrm{C}$ versus linear polystyrene. [d] $8 \mathrm{~h}$. [e] diallyl ether, 450 equiv [f] $95^{\circ} \mathrm{C}$. [g] Allyl ethyl ether: 225 equiv.

(Table 3, entries 2 5). ${ }^{[20,21]}$ Their microstructures essentially resemble those of the DAE repeat units in the aforemen tioned E DAE copolymers (Supporting Information, Fig ure S25). Degrees of polymerization amounted to up to $\mathrm{DP}_{\mathrm{n}}$ $\approx 44\left(M_{\mathrm{n}}=4350 \mathrm{~g} \mathrm{~mol}^{-1}\right)$ (Supporting Information, Figur es S26 S29). Further control experiments essentially rule out a free radical or cationic mechanism of chain growth (Table 3, entries 6 and 7). Such polymerizations occurred with much lower productivities to give lower molecular weight products $\left(M_{\mathrm{n}}<500 \mathrm{~g} \mathrm{~mol}^{-1}\right)$ with a completely different microstructure (Supporting Information, Figure S25). By contrast to this insertion homopolymerization of diallyl ether monomer DAE, exposure of mono allyl ether monomer AEE to 1 resulted in the formation of a much lower molecular weight product with $\mathrm{DP}_{\mathrm{n}} \approx 2$ with a low productivity (Table 3 , entries 8 versus 2).

In summary, the utilization of diallyl ether as a monomer allows for a much enhanced incorporation of an allyl monomer in insertion copolymerizations. This overcomes the thus far relatively low incorporation of allyl co monomers (and of electron rich co monomers in general). Even homo polymerizations are possible, which thus far are difficult for allyl monomers by any polymerization mechanism. This particular reactivity can be accounted for by an altered or even inverted regioselectivity of insertion for the $\mathrm{CH}_{2}=$ $\mathrm{CHCH}_{2} \mathrm{OR}$ allylic double bond of diallyl ether $\left(\mathrm{R}=\mathrm{CH}_{2} \mathrm{CH}=\right.$ $\mathrm{CH}_{2}$ ) versus other allyl ethers (such as $\mathrm{R}=\mathrm{Et}$ ). This disfavors the otherwise predominant 1,2 insertion pathway that leads to a stable and unreactive five membered cyclic $O$ chelate with the ether oxygen atom of the inserted monomer unit binding to the metal center. A consecutive intramolecular insertion of the second allyl moiety of the monomer very selectively forms cyclic ether repeat units, with a clear preference for five membered cyclic tetrahydrofuran motifs.

\section{Acknowledgements}

Z.J. is grateful to the Alexander von Humboldt Foundation for a postdoctoral research fellowship and to the University of Konstanz for support within the EU FP7 Marie Curie Zukunftskolleg Incoming Fellowship Programme (grant no. 291784). Inigo Göttker Schnetmann is gratefully acknowl edged for helpful discussions. The authors also thank Lars Bolk for GPC and DSC experiments, Anke Friemel and Ulrich Haunz for support with NMR measurements.

Keywords: allyl monomer · homogeneous catalysis · insertion . palladium - polymerization

How to cite: Angew. Chem. Int. Ed. 2015, 54, 1584515849 Angew. Chem. 2015, 127, 1607116075

[1] R. C. Laible, Chem. Rev. 1958, 58, 807.

[2] Radical polymerizations have been reported to afford high molecular weight polymers in the presence of additional Brønsted or Lewis acids; see: a) K. Iio, K. Kobayashi, M. Matsuo, Polym. Adv. Technol. 2007, 18, 953; b) S. Harada, S. Hasegawa, Makromol. Chem. Rapid Commun. 1984, 5, 27.

[3] S. Aoshima, S. Kanaoka, Chem. Rev. 2009, 109, 5245.

[4] D. Takeuchi, MRS Bull. 2013, 38, 252.

[5] a) B. P. Carrow, K. Nozaki, J. Am. Chem. Soc. 2012, 134, 8802; b) S. Ito, Y. Ota, K. Nozaki, Dalton Trans. 2012, 41, 13807; c) S. Ito, M. Kanazawa, K. Munakata, J. Kuoda, Y. Okumura, K. Nozaki, J. Am. Chem. Soc. 2011, 133, 1232.

[6] J. C. Daigle, L. Piche, A. Arnold, J. P. Claverie, ACS Macro Lett. 2012, 1, 343.

[7] M. R. Radlauer, A. K. Buckley, L. M. Henling, T. Agapie, J. Am. Chem. Soc. 2013, 135, 3784.

[8] a) S. Mecking, L. K. Johnson, L. Wang, M. Brookhart, J. Am. Chem. Soc. 1998, 120, 888; b) L. K. Johnson, S. Mecking, M. Brookhart, J. Am. Chem. Soc. 1996, 118, 267.

[9] a) E. Drent, R. van Dijk, R. van Ginkel, B. van Oort, R. I. Pugh, Chem. Commun. 2002, 744; b) S. Luo, J. Vela, G. R. Lief, R. F. Jordan, J. Am. Chem. Soc. 2007, 129, 8946; c) T. Kochi, S. Noda, K. Yoshimura, K. Nozaki, J. Am. Chem. Soc. 2007, 129, 8948; d) W. Weng, Z. Shen, R. F. Jordan, J. Am. Chem. Soc. 2007, 129, 15450; e) S. Ito, K. Munakata, A. Nakamura, K. Nozaki, J. Am. Chem. Soc. 2009, 131, 14606; f) D. Guironnet, P. Roesle, T. Rünzi, I. Göttker Schnetmann, S. Mecking, J. Am. Chem. Soc. 2009, 131, 422; g) T. Rünzi, D. Fröhlich, S. Mecking, J. Am. Chem. Soc. 2010, 132, 17690; h) T. Friedberger, P. Wucher, S. Mecking, J. Am. Chem. Soc. 2012, 134, 1010; i) L. Piche, J. C. Daigle, G. Rehse, J. P. Claverie, Chem. Eur. J. 2012, 18, 3277; j) H. Leicht, I. Göttker Schnetmann, S. Mecking, Angew. Chem. Int. Ed. 2013, 52, 3963; Angew. Chem. 2013, 125, 4055; k) D. Lanzinger, M. M. Giuman, T. M. J. Anselment, B. Rieger, ACS Macro Lett. 2014, 3, 931; 1) Y. Ota, S. Ito, J. Kuroda, Y. Okumura, K. Nozaki, J. Am. Chem. Soc. 2014, 136, 11898.

[10] Reviews: a) A. Berkefeld, S. Mecking, Angew. Chem. Int. Ed. 2008, 47, 2538; Angew. Chem. 2008, 120, 2572; b) A. Nakamura, S. Ito, K. Nozaki, Chem. Rev. 2009, 109, 5215; c) E. Y. X. Chen, Chem. Rev. 2009, 109, 5157; d) A. Nakamura, T. M. J. Ansel ment, J. P. Claverie, B. Goodall, R. F. Jordan, S. Mecking, B. Rieger, A. Sen, P. W. N. M. van Leeuwen, K. Nozaki, Acc. Chem. 
Res. 2013, 46, 1438; e) B. P. Carrow, K. Nozaki, Macromolecules 2014, $47,2541$.

[11] Note that cationic $\alpha$ diimine palladium catalysts were reported to not promote a copolymerization of AEE and E: W. Li, X. Zhang, A. Meetsma, B. Hessen, J. Am. Chem. Soc. 2004, 126, 12246.

[12] The copolymerization of ADEA and E affords a copolymer with low incorporation, but the resulting copolymer can be readily converted into an $\mathrm{E}$ acrolein copolymer that cannot be obtained from the reaction of $\mathrm{E}$ and acrolein directly; Supporting Information, Figures S68 and S69.

[13] Z. Jian, M. C. Baier, S. Mecking, J. Am. Chem. Soc. 2015, 137, 2836.

[14] A. Ravasio, L. Boggioni, I. Tritto, Macromolecules 2011, 44, 4180.

[15] In the ethylene vinyl ether copolymer, vinyl ether is also not detected at terminating chain ends. See Ref. [9b].

[16] Trans selectivity is preferred owing to the steric repulsion of two substituents on the rings ( 3,4 in a five membered cyclic structure II and 3,5 in a six membered cyclic structure III). Generally, the steric repulsion of 3,4 di substituents is larger than that of 3,5 di substituents. In reported ethylene acrylic anhydride copolymers (see Ref. [13]), a preferred trans selectivity of 3,4 di substituents in a five membered cyclic structure was also observed and confirmed by a crystal structure of an analogue.

[17] The microstructure of the copolymer from the reaction of ethylene and 2,5 dihydrofuran is complex in that it contains 3,4 disubstituted (analogous to the five membered cyclic structure II) as well as 2,3 disubstituted tetrahydrofuran motifs, and further unidentifiable structures.
[18] In the kinetic experiments, 1,2 insertion of DAE into the Pd Me bond is preferred, but 2,1 insertion of DAE into more bulky palladium alkyl bonds appears to be favored. In the copoly merization experiments, the insertion of DAE into the Pd Me bond to form chain ends is only an initiating step, and the 2,1 insertion of DAE into palladium polyethylene growing chains (more bulky palladium alkyls) to form in chain five membered cyclic structure II is the favored step.

[19] CCDC 1060855 (9) contains the supplementary crystallographic data for this paper. These data are provided free of charge by The Cambridge Crystallographic Data Centre.

[20] Note that using a zirconocene catalyst, 4 trimethylsiloxy 1,6 heptadiene but not DAE could be homopolymerized: a) M. R. Kesti, G. W. Coates, R. M. Waymouth, J. Am. Chem. Soc. 1992, 114, 9679; also cf. b) E. A. Bijpost, M. A. Zuideveld, A. Meet sma, J. H. Teuben, J. Organomet. Chem. 1998, 551, 159.

[21] For cyclopolymerizations of nonfunctionalized dienes, see: a) G. W. Coates, R. M. Waymouth, J. Am. Chem. Soc. 1991, 113, 6270; b) X. Shi, Y. Wang, J. Liu, D. Cui, Y. Men, Y. Li, Macromolecules 2011, 44, 1062; c) K. E. Crawford, L. R. Sita, J. Am. Chem. Soc. 2013, 135, 8778; for reactions of functionalized 1,6 dienes catalyzed by $\alpha$ diimine $\mathrm{Pd}^{\mathrm{II}}$ catalysts, see: d) T. Okada, S. Park, D. Takeuchi, K. Osakada, Angew. Chem. Int. Ed. 2007, 46, 6141; Angew. Chem. 2007, 119, 6253; e) S. Park, D. Takeuchi, K. Osakada, J. Am. Chem. Soc. 2006, 128, 3510. 